\title{
Peritoneal metastasis in gastric cancer: results from the German database
}

\author{
Beate Rau ${ }^{1}\left(\mathbb{0} \cdot\right.$ Andreas Brandl $^{1} \cdot$ Pompiliu Piso ${ }^{2} \cdot \mathrm{Jörg} \mathrm{Pelz}^{3} \cdot$ Peter Busch $^{4} \cdot$ Cedric Demtröder $^{5} \cdot$ Silke Schüle $^{6}$. \\ Hans-Jürgen Schlitt ${ }^{7}$ Marc Roitman ${ }^{8}$. Jürgen Tepel ${ }^{9} \cdot$ Udo Sulkowski $^{10} \cdot$ Faik Uzunoglu $^{11} \cdot$ Michael Hünerbein $^{12}$. \\ Rüdiger Hörbelt ${ }^{13}$. Michael Ströhlein ${ }^{14}$. Stefan Beckert ${ }^{15}$. Ingmar Königsrainer ${ }^{15}$. Alfred Königsrainer ${ }^{15} \cdot$ for the $^{\text {. }}$ \\ Peritoneum Surface Oncology Group and members of the StuDoQ|Peritoneum Registry of the German Society for \\ General and Visceral Surgery (DGAV)
}

Received: 5 December 2018 / Accepted: 5 June 2019 / Published online: 21 June 2019

(c) The International Gastric Cancer Association and The Japanese Gastric Cancer Association 2019

\begin{abstract}
Background Patients with peritoneal metastases of gastric cancer have a poor prognosis with a median survival of 7 months. A benefit of cytoreductive surgery (CRS) and hyperthermic intraperitoneal chemotherapy (HIPEC) could be shown in several selected patient cohorts but remains controversial. The aim of this study was, to reflect the results of a national German HIPEC registry initiated by the German Society of General and Visceral Surgery (DGAV).

Methods The DGAV HIPEC registry StuDoQ|Peritoneum documents patients with peritoneal malignancy contributed from 52 hospitals. All consecutive documented patients from 2011 until $2016(n=3078)$ were treated with CRS and HIPEC and were analysed. A total of $315(10 \%)$ suffered from gastric cancer and were analysed.

Results A complete data set of 235 patients was available for this study, including 113 male (48.1\%) and 122 female (51.9\%) patients with a median age of 53.4 years ( $\mathrm{SD} \pm 11.9$ ). The median PCI was 8.0 (range 1-30). A complete cytoreduction was achieved in 121 patients (71.6\%). Postoperative complications (Clavien-Dindo grades 3-4) occurred in 40 patients (17\%). The median overall survival (OS) time was 13 months. The 5-year survival rate was 6\%. According to the PCI from 0-6 $(n=74)$; $7-15(n=70)$ and 16-39 $(n=24)$ the median OS differs significantly (18 months vs. 12 months vs. 5 months; $p=0.002)$.

Conclusions CRS and HIPEC in selected patients with gastric cancer and peritoneal spread can improve survival when they are treated in centers. An accurate staging and patient selection are of major importance to achieve long-term survival.
\end{abstract}

Keywords Peritoneal metastases · Gastric cancer · Cytoreductive surgery · Hyperthermic intraperitoneal chemotherapy

\section{Introduction}

Gastric cancer (GC) representing $10 \%$ of all cancers is the fifth most common cancer worldwide, shifting from its spot as the most common malignancy in the last 40 years. In spite of this change, it remains the third leading cause of death associated with cancer (723 000 deaths) [1].

The NCCN Guidelines for GC provide evidence- and consensus-based recommendations for a multidisciplinary

Beate Rau, Andreas Brandl are contributed equally to this manuscript.

\section{Beate Rau}

beate.rau@charite.de

Extended author information available on the last page of the article approach. In patients with resectable locoregional cancer, gastrectomy with lymph node dissection after induction chemotherapy in T3 and/or N+ tumors [2], and in disseminated disease systemic palliative chemotherapy is recommended independently of organ or peritoneal metastasis. Peritoneal involvement can be present at primary diagnosis or occur after completion of the treatment in the follow-up.

Risk factors for peritoneal metastasis (PM) are: T3 and $\mathrm{T} 4$ tumors, lymph node invasion, signet ring cell histology, diffuse infiltrative growth pattern, and primary scirrhoustype tumor. The impact of systemic chemotherapy in metastatic patients is limited [3, 4]. A response rate of nearly $40 \%$ can be expected in liver-, lung-, or bone metastasis, whilst the response rate for patients with PM is less than $14 \%$ [5]. One reason for this is a barrier between blood and peritoneum that prevents drug penetration in the peritoneal 
layer [5]. The incidence of PM is frequent and observed in $10-20 \%$ of patients scheduled for primary surgery, and up to $40 \%$ in extended disease like stage III GC [6].

In a systematic review by Di Vita et al. the authors concluded that surgery in GC with peritoneal metastases is an option and should be performed in selected cases when a complete cytoreduction can be achieved [7]. Cytoreductive surgery (CRS) should include resection of the primary tumor with acceptable margins, any adjacent structures involved, lymphadenectomy in levels I and II, and the resection of every visible PM, according to the peritonectomy procedure developed by Sugarbaker $[8,9]$. This recommendation was confirmed in a meta-analysis by Sun et al. [10]. The results of this meta-analysis showed that palliative gastrectomy for patients with incurable advanced GC may be associated with longer survival. Patients with liver metastases had a better outcome compared to patients with PM. However, even in selected cases with PM chemotherapy remains the most important tool in the treatment [11].

Chemotherapy can also be delivered intraperitoneally. Hyperthermic intraperitoneal chemotherapy (HIPEC) has been shown to be an effective treatment, whenever a complete or an almost complete resection of the PM can be achieved. For this invasive treatment, patients have to be in good condition, which is often compromised in advanced GC. A benefit of CRS and HIPEC in these patients could be shown in several selected patient cohorts, but remains controversial.

National registries such as the BIG RENAPE (Base clinic-biologique des carcinoses peritoneales d' origine Digestive du Reseau National de Prise en charge des Tumeurs du Peritoine) in France or recently the Brazilian Registry of Peritoneal Diseases (BRPD), and other national registries provide data from multicenter patient's series [12, 13]. In cooperation with the international peritoneal surface malignancy group (PSOGI), an excellent exchange of knowledge is provided [14].

The German Society of General and Visceral Surgery (DGAV) from 2008 on started a close data management for new surgical techniques as well as a surgical quality assessment with a national registry and an accreditation. The aim was education, and to specify recommendations concerning safety, auditing indications and perioperative outcome. The hospitals have the option to certify for different levels according to their treatment volume and academic translational programs.

Special software was developed for online data collection. Participants receive a comprehensive statistical evaluation of their own data, including benchmark with the overall registry data.

Data are collected online in a customizable input mask. A flexible adjustable error and plausibility checking ensures optimal data quality. Entered data can be exported in various export formats (Excel, SPSS, and CSV) and downloaded by the participating institution at any time. In addition, participants once a year will receive an automatic online report. By export opportunities, a high transparency is provided, as an analysis of the entered data at the institutional level is possible. The software provides a data export for the certification process according to the regulations of the German Cancer Society (OnkoZert).

The purpose of this study was to present the results of the German HIPEC register on CRS and HIPEC in GC with PM, focusing on the key items, from the database. According to our knowledge, this paper described the largest experience in patients treated surgically with CRS and HIPEC for GC with PM ever published.

\section{Patients and methods}

The DGAV HIPEC registry StuDoQIPeritoneum, introduced in 2011 including 3078 consecutive treated patients with CRS and HIPEC until 2016, was retrospectively analysed for this study. The data were administrated by the German Society for General and Visceral Surgery. A total of 52 hospitals contributed to the registry, and in $315(10 \%)$ patients, the primary tumour was from a gastric cancer origin (10\%).

Due to the retrospective character of the analysis of the anonymised data, no institutional review board approval was needed. All patients gave the informed consent for data recording in the registry and were treated according to a multidisciplinary recommendation. Some patients were included in ongoing clinical trials.

The database includes all relevant parameters related to patient`s characteristics, type and extent of peritoneal disease, previous treatments, and details of CRS and HIPEC including short and long-term outcomes.

\section{Patient selection}

235 out of 315 GC patients (74.6\%) treated in 38 centres were analysed. Only patients with pathological confirmed synchronous PM of GC and complete treatment including gastrectomy and HIPEC were included in the analysis. 51 patients had no gastrectomy (16.2\%) and were similarly excluded as 29 patients (9.2\%) with incomplete data. Preoperative chemotherapy (FLOT, EOX, FOLFOX, and FOLFIRI) was used in the majority of the patients [15].

\section{Cytoreductive surgery}

The CRS procedure aims for complete tumor resection, including oncological resection of the primary GC analogue to the existing guidelines combined with complete macroscopic peritonectomy of tumor infiltrated areas of the 
peritoneum [2]. The extend of PM was measured according to the peritoneal carcinomatosis index (PCI) introduced by Jacquet and Sugarbaker [16] (Fig. 1).

The completeness of cytoreduction, influenced by the extent of the peritoneal tumor manifestation is the strongest prognostic factor for patient survival. Therefore, the aim of CRS is to obtain complete macroscopic cytoreduction (CCR0/1). CCR-0 indicates no visible residual tumor and CCR-1 residual tumor nodules $\leq 2.5 \mathrm{~mm}$. CCR-2 and CCR-3 indicate residual tumor nodules between $2.5 \mathrm{~mm}$ and $2.5 \mathrm{~cm}$ and $>2.5 \mathrm{~cm}$, respectively [17].

\section{Hyperthermic intraperitoneal chemotherapy (HIPEC)}

The HIPEC application was open or closed, synchronous or metachronous following the safety criteria of the hospital. Drugs as well as duration of the HIPEC procedure was chosen according to the preference of the centre. Cisplatin, Mitomycin C, doxorubicin, and oxaliplatin were mostly used as HIPEC drugs. The duration of HIPEC differs from 30 to 90 min with a mean temperature of $42^{\circ} \mathrm{C}$.

\section{Postoperative care}

All patients postoperatively were admitted to an intensive care unit (ICU). For postoperative morbidity, the Clavien-Dindo classification was applied [18].
Histopathology was classified to the international guidelines [19]. All patients had a standardized followed up. Adjuvant systemic chemotherapy was given depending on a subsequent MDT recommendation.

OS was defined as the time between CRS \& HIPEC and the last follow-up of the patient.

\section{Statistic}

All statistical analyses were performed using SPSS 23.0 (International Business Machines Corporation, Armonk, NY, USA). Continuous descriptive data are given as mean and standard deviation or median and interquartile range, depending on their distribution. Categorical data are given as frequencies and proportions. Univariate analysis of time to event data was performed using log-rank test to compare several groups. Univariate results were visualized by Kaplan-Meier curves. The variables: underlying disease, gender, age, BMI, operation time, comorbidities, ASA classification, PCI, CC, time from diagnosis to CRS and HIPEC and number of anastomosis were included in the model. The backward stepwise variable selection with a kaike information criterion (AIC) method was used. A $p$ value below 0.05 was considered to be significant.


Lesion Size Score

LS 0 No tumor seen

LS I Tumor up to $0.5 \mathrm{~cm}$

LS 2 Tumor up to $5.0 \mathrm{~cm}$

LS 3 Tumor $>5.0 \mathrm{~cm}$

or confluence



Fig. 1 Peritoneal Cancer Index (PCI), with kind permission of Paul Sugarbaker [16] 


\section{Results}

\section{Characteristics}

A complete data set of 235 patients was available for this study. 113 of the patients were male $(48.1 \%)$ and 122 were female $(51.9 \%)$, and the median age was 53.4 years $(\mathrm{SD} \pm 11.9)$.

The details of patients coming from 16 recruiting centres are depicted in Table 1. Nearly half $(49.4 \%)$ of patients were treated in 4 high-volume centres with more than 20 cases each.

Preoperative systemic chemotherapy was applied in 174 patients $(74.0 \%)$, using a docetaxel-based protocol in the majority of the patients. The overall length of intensive care unit (ICU) and hospital stay was 23.5 days ( $\mathrm{SD} \pm 14.3$ ) and 6.9 days $(\mathrm{SD} \pm 13.4)$, respectively (Table 2 ).

\section{Surgery}

The median PCI was 8.0 (range 1-30), and 78 patients (46.4\%) had a $\mathrm{PCI} \leq 7$. A macroscopic complete cytoreduction, CCR 0 was achieved in 121 of 169 patients (71.6\%).

According to the inclusion criteria, all patients underwent total or partial gastrectomy. The incidence and type of resection of additional organs to reach a CCR 0 status are listed in Table 2. Peritonectomy of the parietal-, pelvis-, left-, and right upper quadrant was performed in $77 \%, 32 \%, 46 \%$, and $40 \%$ of the patients, respectively.

\section{HIPEC}

For the HIPEC application, the majority of hospitals used a closed (184 patients; $78.3 \%$ ) technique. The mean temperature was $41.7^{\circ} \mathrm{C}(\mathrm{SD} \pm 0.7)$ and the mean duration of intraabdominal chemotherapy was $62.5(\mathrm{SD} \pm 17.9) \mathrm{min}$.

Table 1 (a) Volume of treated patients with peritoneal metastatic gastric cancer in participating hospitals, (b) factors of treated patients with peritoneal metastatic gastric cancer according to the experience of the center

\begin{tabular}{|c|c|c|c|c|}
\hline Included patients & \multicolumn{2}{|c|}{ Number of Hospitals } & \multicolumn{2}{|c|}{$\begin{array}{l}\text { Total number } \\
\text { of patients } \% \\
(n=235)\end{array}$} \\
\hline $1-3$ & \multicolumn{2}{|c|}{3} & \multicolumn{2}{|c|}{$25(10.6 \%)$} \\
\hline $4-10$ & \multicolumn{2}{|c|}{4} & \multicolumn{2}{|c|}{$44(18.7 \%)$} \\
\hline $11-20$ & \multicolumn{2}{|c|}{5} & \multicolumn{2}{|c|}{$50(21.3 \%)$} \\
\hline$>20$ & \multicolumn{2}{|c|}{4} & \multicolumn{2}{|c|}{$116(49.4 \%)$} \\
\hline Factor & Total $(n=235)$ & $\begin{array}{l}\text { Low-volume center }(<20 \\
\text { cases })(n=119)\end{array}$ & $\begin{array}{l}\text { High-volume center }(>20 \\
\text { cases) }(n=116)\end{array}$ & $p$ value \\
\hline Female & $122(51.9 \%)$ & $57(47.9 \%)$ & $65(56.0 \%)$ & 0.13 \\
\hline Synchronous HIPEC & $185(78.7 \%)$ & $78(65.5 \%)$ & $107(92.2 \%)$ & $<0.001$ \\
\hline Closed HIPEC technique & $184(78.3 \%)$ & $88(73.9 \%)$ & $96(82.8 \%)$ & 0.07 \\
\hline Splenectomy & $69 / 218(31.7 \%)$ & $37 / 106(34.9 \%)$ & $32 / 112(28.6 \%)$ & 0.20 \\
\hline Pancreas resection & $36 / 211(17.1 \%)$ & $17 / 100(17.0 \%)$ & $19 / 111(17.1 \%)$ & 0.57 \\
\hline \multicolumn{5}{|l|}{ CC Score } \\
\hline $\mathrm{CC} 0$ & $121 / 169(71.6 \%)$ & $63 / 101(62.4 \%)$ & $58 / 68(85.3 \%)$ & 0.001 \\
\hline Incomplete cytoreduction & $48 / 169(28.4 \%)$ & $38 / 101(37.6 \%)$ & $10 / 68(14.7 \%)$ & \\
\hline Preoperative chemotherapy & $174 / 221(78.7 \%)$ & $78 / 105(74.3 \%)$ & $96(82.8 \%)$ & 0.09 \\
\hline Postoperative complications & & & & 0.03 \\
\hline Grade I and II & $165 / 217(76.0 \%)$ & $69 / 104(66.3 \%)$ & $96 / 113(85.0 \%)$ & \\
\hline Grade IIIa & $11 / 217(5.1 \%)$ & $9 / 104(8.7 \%)$ & $2 / 113(1.8 \%)$ & \\
\hline Grade IIIb & $19 / 217(8.8 \%)$ & $11 / 104(10.6 \%)$ & $8 / 113(7.1 \%)$ & \\
\hline Grade IV & $10 / 217(4.6 \%)$ & $6 / 104(5.8 \%)$ & $4 / 113(3.5 \%)$ & \\
\hline Grade V & $12 / 217(5.5 \%)$ & $9 / 104(8.7 \%)$ & $3 / 113(2.7 \%)$ & \\
\hline Operation time $(\min )$ & $376.3 \pm 150.9$ & $396.7 \pm 174.9$ & $355.4 \pm 118.7$ & 0.04 \\
\hline ICU stay (days) & $6.9 \pm 14.3$ & $6.6 \pm 10.0$ & $7.1 \pm 16.1$ & 0.75 \\
\hline PCI total & $8.6 \pm 6.7$ & $9.3 \pm 6.0$ & $7.6 \pm 6.5$ & 0.09 \\
\hline Patient age (years) & $53.5 \pm 11.9$ & $53.5 \pm 11.9$ & $53.4 \pm 11.8$ & 0.92 \\
\hline Overall survival (months) & $10.8 \pm 13.3$ & $8.7 \pm 8.4$ & $13.0 \pm 17.2$ & 0.05 \\
\hline Disease-free survival (months) & $8.0 \pm 8.5$ & $6.6 \pm 6.4$ & $9.7 \pm 10.1$ & 0.03 \\
\hline
\end{tabular}


Table 2 Characteristics of the 235 patients

\begin{tabular}{|c|c|c|c|}
\hline Variable & $N$ & $\%$ total $(n=235)$ & Missing values \\
\hline \multicolumn{4}{|l|}{ (a) Patient characteristics } \\
\hline \multicolumn{4}{|l|}{ Gender } \\
\hline Male & 113 & 28.1 & \\
\hline Female & 122 & 51.9 & \\
\hline Age & $53.4 \pm 11.9$ & & \\
\hline \multicolumn{4}{|l|}{ Histological Type } \\
\hline Adenocarcinoma & 154 & 65.5 & $19(8.1 \%)$ \\
\hline Signet ring cell carcinoma & 59 & 25.1 & \\
\hline Other & 3 & 1.3 & \\
\hline \multicolumn{4}{|l|}{ Histology } \\
\hline Mucinous & 25 & 10 & $69(29.4 \%)$ \\
\hline Well & 4 & 1.7 & $78(33.2 \%)$ \\
\hline Moderately & 35 & 14.9 & $78(33.2 \%)$ \\
\hline Poor & 118 & 50.2 & $71(30.2 \%)$ \\
\hline Signet ring cell & 114 & 48.5 & $9(3.8 \%)$ \\
\hline Hospital stay (days) & $23.5+14.3$ & & \\
\hline ICU stay (days) & $6.9+14.3$ & & \\
\hline \multicolumn{4}{|l|}{ (b) Chemotherapeutic characteristics } \\
\hline \multicolumn{4}{|l|}{ Preoperative chemotherapy } \\
\hline Yes & 174 & 74.0 & $14(6 \%)$ \\
\hline No & 47 & 20.0 & \\
\hline No chemo & 62 & 26.4 & \\
\hline Drug not stated & 15 & 6.4 & \\
\hline FLOT & 80 & 34.0 & \\
\hline $\mathrm{ECF}$ & 19 & 8.1 & \\
\hline EOX & 18 & 7.7 & \\
\hline DCF & 11 & 4.7 & \\
\hline FLO & 8 & 3.4 & \\
\hline $\mathrm{CF}$ & 7 & 3.0 & \\
\hline FOLFOX & 3 & 1.3 & \\
\hline PLF & 3 & 1.3 & \\
\hline RCT-Radio & 2 & 0.9 & \\
\hline $5-\mathrm{FU}$ & 1 & 0.4 & \\
\hline $\mathrm{CFF}$ & 1 & 0.4 & \\
\hline Cisplatin & 1 & 0.4 & \\
\hline Etoposid & 1 & 0.4 & \\
\hline FOLFIRI & 1 & 0.4 & \\
\hline Oxaliplatin & 1 & 0.4 & \\
\hline XELOX & 1 & 0.4 & \\
\hline \multicolumn{4}{|l|}{ HIPEC } \\
\hline Metachronous & 50 & 21.3 & \\
\hline Synchronous & 185 & 78.7 & \\
\hline Open & 51 & 21.7 & \\
\hline Closed & 184 & 78.3 & \\
\hline Mono Chemotherapy & 62 & 26.4 & \\
\hline Dual combination & 173 & 73.6 & \\
\hline Cisplatin and Doxorubicin & 123 & $53 \%$ & \\
\hline Cisplatin and Mitomycin C & 43 & $18 \%$ & \\
\hline $\begin{array}{l}\text { Oxaliplatin and Mitomycin } \mathrm{C} \text { or } \\
\text { Doxorubicin }\end{array}$ & 5 & $2 \%$ & \\
\hline
\end{tabular}


Table 2 (continued)

\begin{tabular}{|c|c|c|c|}
\hline Variable & $N$ & $\%$ total $(n=235)$ & Missing values \\
\hline MMC and Doxorubicin & 2 & $1 \%$ & \\
\hline Cisplatin & 15 & $6 \%$ & \\
\hline Oxaliplatin & 5 & $2 \%$ & \\
\hline Mitomicin C & 37 & $16 \%$ & \\
\hline OTH & 4 & $2 \%$ & \\
\hline HIPEC-Temp $\left({ }^{\circ} \mathrm{C}\right)$ & $41.7+0.7$ & & $14(6 \%)$ \\
\hline HIPEC-Dauer (min) & $62.5+17.9$ & & \\
\hline \multicolumn{4}{|l|}{ (c) Surgical characteristics } \\
\hline OP Duration (min) & $376.3+150.9$ & & \\
\hline \multicolumn{4}{|l|}{ CC Score } \\
\hline CC 0 (complete resection) & 121 & 51.5 & $66(28.1 \%)$ \\
\hline $\mathrm{CC} 1(\leq 0.25 \mathrm{~cm})$ & 34 & 14.5 & \\
\hline $\mathrm{CC} 2(0.25-2.5 \mathrm{~cm})$ & 10 & 4.3 & \\
\hline $\mathrm{CC} 3(\geq 2.5 \mathrm{~cm})$ & 4 & 1.7 & \\
\hline \multicolumn{4}{|l|}{ Resection } \\
\hline Omentum majus resection & Omentum majus resection & Omentum majus resection & Omentum majus resection \\
\hline Cholecystectomy & Cholecystectomy & Cholecystectomy & Cholecystectomy \\
\hline Omentum minus resection & Omentum minus resection & Omentum minus resection & Omentum MINUS RESECTION \\
\hline Colonic resection & Colonic resection & Colonic resection & Colonic resection \\
\hline Splenectomy & Splenectomy & Splenectomy & Splenectomy \\
\hline Small bowel resection & Small bowel resection & Small bowel resection & Small bowel resection \\
\hline Ovarectomy & Ovarectomy & Ovarectomy & Ovarectomy \\
\hline OTH & OTH & OTH & OTH \\
\hline Pancreatic resection & Pancreatic resection & Pancreatic resection & Pancreatic resection \\
\hline Low anterior rectal resection & Low anterior rectal resection & Low anterior rectal resection & Low anterior rectal resection \\
\hline Liver resection & Liver resection & Liver resection & Liver resection \\
\hline Hysterectomy & Hysterectomy & Hysterectomy & Hysterectomy \\
\hline Cystectomy & Cystectomy & Cystectomy & Cystectomy \\
\hline \multicolumn{4}{|l|}{ R Score } \\
\hline R0 & 95 & 40.4 & $93(39.6 \%)$ \\
\hline $\mathrm{R} 1$ & 39 & 16.6 & \\
\hline $\mathrm{R} 2 \mathrm{a}$ & 6 & 2.6 & \\
\hline $\mathrm{R} 2 \mathrm{c}$ & 2 & 0.9 & \\
\hline
\end{tabular}

The HIPEC was given immediately after cytoreduction in 185 patients (78.7\%) and in 50 patients (21.3\%) on a different day. The mean interval between surgery and HIPEC in these cases was 6.9 days $(\mathrm{SD} \pm 0.84)$.

Cisplatin, Mitomycin C, doxorubicin, and oxaliplatin were mostly used as HIPEC drugs. Usually, two drugs $(n=173 ; 73.6 \%)$ were simultaneously applied. The most common combination was cisplatin and doxorubicin in 123 patients (53\%) followed by the combination of cisplatin and Mitomycin C for 43 patients (18.4\%). Single-drug HIPEC with Mitomycin $\mathrm{C}$ was given in 37 patients $(15.8 \%)$, cisplatin in 15 patients $(6.4 \%)$, and oxaliplatin in 5 patients $(0.2 \%)$. The median dosage of cisplatin was $75 \mathrm{mg} / \mathrm{m}^{2}$, doxorubicin $15 \mathrm{mg} / \mathrm{m}^{2}$ mitomycin C $30 \mathrm{mg} / \mathrm{m}^{2}$ and oxaliplatin $300 \mathrm{mg} / \mathrm{m}^{2}$ (Table 2).

\section{Complications}

Clavien-Dindo grade 3-4 complications occurred in 40 patients $(17 \%)$. Twelve patients $(5.1 \%)$ died due to postoperative complications. Six $(2.6 \%)$ of them due to an anastomotic leakage, three (1.2\%) of multiorgan failure, one $(0.4 \%)$ of meningiosis carcinomatosis, one $(0.4 \%)$ of severe pneumonia, and one patient $(0.4 \%)$ developed renal failure (Table 3).

\section{Outcome}

The mean follow-up was $10.8 \pm 11.9$ months. Hospitals with a lower number of treated patients (less than 20) the followup period was $8.7 \pm 1.0$ months and $7.6 \%$ of the patient died 
Table 3 Complications according to the Clavien-Dindo classification

\begin{tabular}{llc}
\hline Complications & $N$ & $\%$ total $(n=235)$ \\
\hline Missing & 18 & 7.7 \\
Grade I and II & 165 & 70.2 \\
Grade IIIa Intervention not under general anesthesia & 11 & 4.7 \\
Grade IIIb Intervention under general anesthesia & 19 & 8.1 \\
Grade IV Life-threatening complication (including CNS complica- & 2 & 0.9 \\
$\quad$ tions) requiring IC/ICU management & & 3.0 \\
Grade IVa Single organ dysfunction (including dialysis) & 7 & 0.4 \\
Grade IVb Multiorgan dysfunction & 1 & 5.1 \\
Grade V Death of a patient & 12 & \\
\hline
\end{tabular}

in the early postoperative course, whereas in four centers with more than 20 patients, the mean observation period was $13.1 \pm 2.1$ month $(p=0.06)$ and $2.6 \%$ of the patients were lost during early postoperative time $(p<0.001)$. The median overall survival (OS) time for the whole group of patients was 13 (95\% CI 9.1-16.9) months. The 5-year survival rate was $6 \%$ (Fig. 2).

We grouped the PCI in three categories from 0 to 6 $(n=74)$ from 7 to $15(n=70)$ and from 16 to $39(n=24)$. In group 1, the median overall survival was 18 months, in group 212 months, and in group 35 months, respectively. The difference was highly significant $(p=0.002)$ (Fig. 3a).

Complete cytoreduction (CCR 0) was achieved in 121 from 169 (71.6\%) patients. The CCR 0 group showed a better long-term survival compared to the incomplete resected group, but failed to reach the level of significance. Though the median survival for CCR 0 was 13 months compared to 10 months $(p=0.19)$, the 1-year and 3-year survival was higher for the CCR 0 group (52.2\% vs. $40.4 \%$ and $20.6 \%$ vs. 8.4\%) (Fig. 3b).

Centers with greater experience treating more than 20 patients achieved a significant better median OS of 16 months compared to centers with less procedure of
12 months; $p=0.02$ ) (Fig. 4). The univariate analysis of patient and procedure-related factors revealed significant differences in time of HIPEC application (synchronous HIPEC rate $92.2 \%$ vs. $65.5 \%$; $p<0.001$ ), complete cytoreduction (CC0 $85.3 \%$ vs. $62.4 \% ; \mathrm{p}=0.001)$, postoperative complications ( $p=0.03$ ), and operation time (355.4 min vs. $396.7 \mathrm{~min} ; p=0.04$ ) comparing high-volume with lowvolume centers (Table 1b).

\section{Discussion}

Patients with peritoneal metastases from GC have a poor prognosis. The guidelines recommend palliative chemotherapy for this stage of disease. Anyhow, due to a better selection process and more aggressive treatment, CRS and HIPEC seem to improve prognosis of patients with PM of GC.

An important prognostic factor is the amount of the peritoneal spread described by the PCI; because the aim to achieve CCR 0 is directly related to the tumor load. In cases of high PCI and small bowel involvement, a complete cytoreduction is rarely possible [20,21]. Therefore,
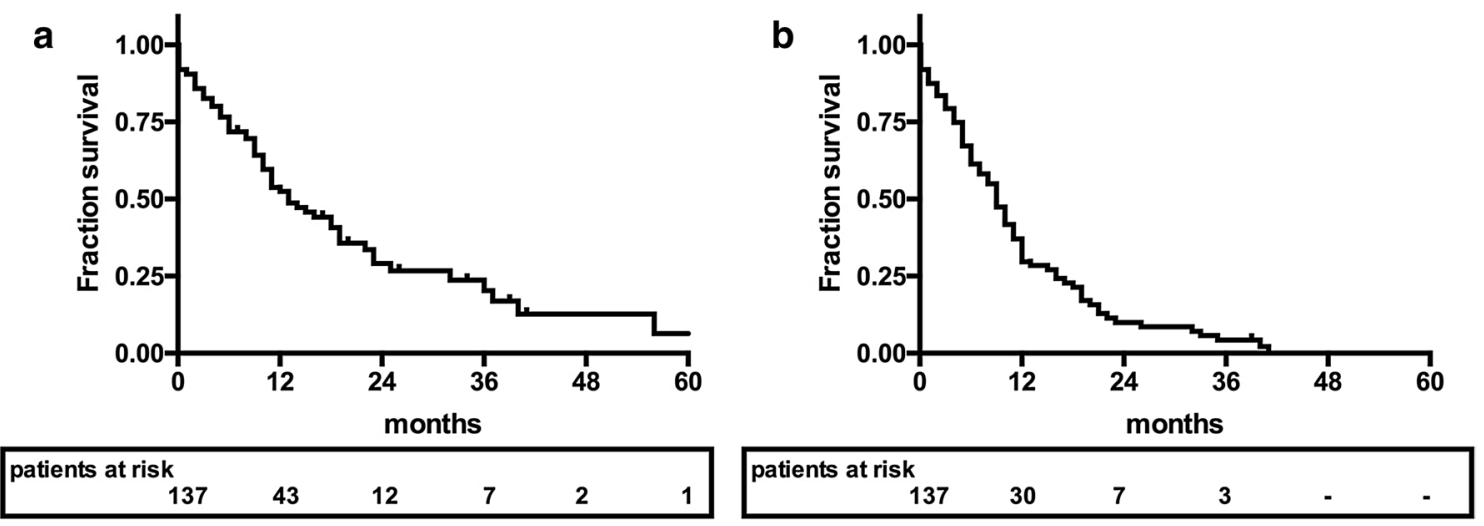

Fig. 2 Overall (a) and disease-free survival (b) of patients with peritoneal metastases of gastric carcinoma treated with cytoreductive surgery and hyperthermic intraperitoneal chemotherapy 
a

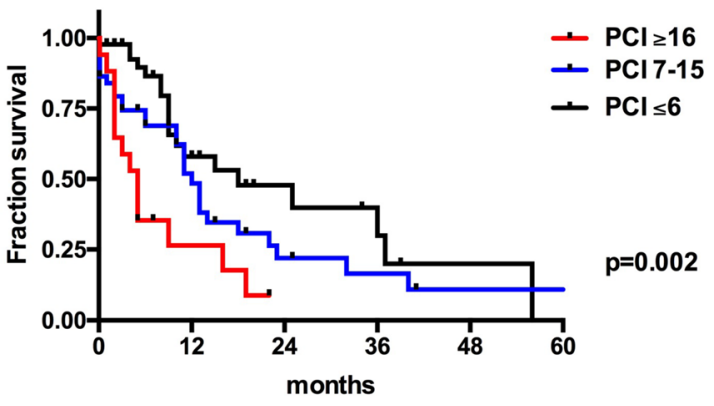

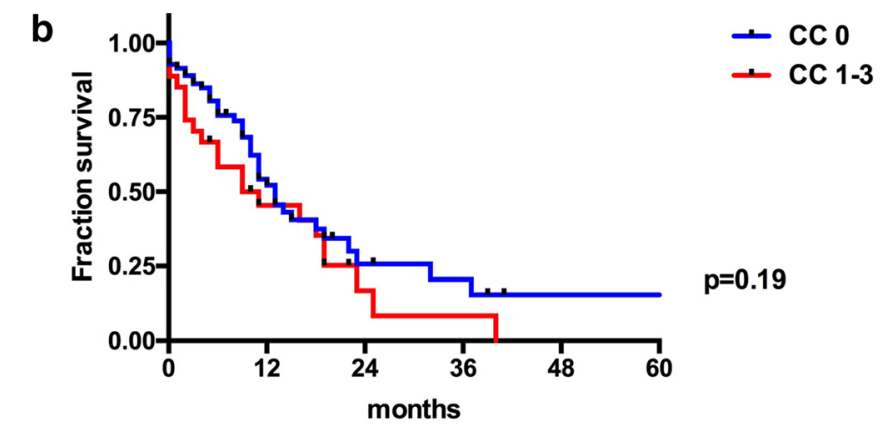

Fig. 3 Overall survival of patients with peritoneal metastases of gastric cancer treated with cytoreductive surgery and hyperthermic intraperitoneal chemotherapy comparing different groups according to
Peritoneal Cancer Index (PCI) $(\mathbf{a} ; p=0.002)$ and according to completeness of cytoreduction $(\mathbf{b} ; p=0.19)$

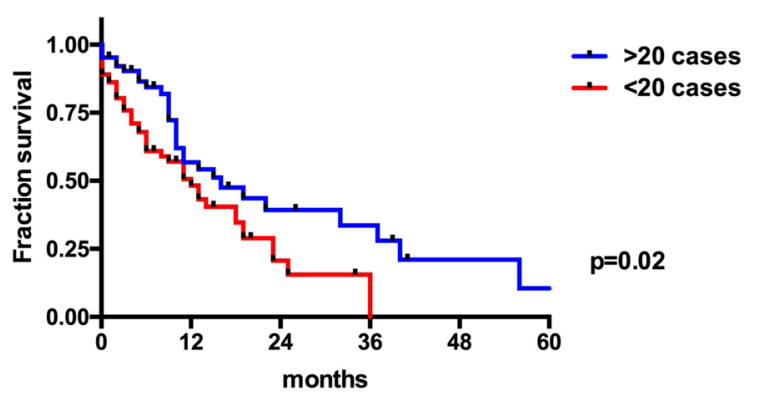

\begin{tabular}{|lllllll|}
\hline \multicolumn{2}{l}{ patients at risk } \\
$>20$ cases & 64 & 22 & 8 & 6 & 2 & 1 \\
$<20$ cases & 73 & 21 & 4 & 1 & - & - \\
\hline
\end{tabular}

Fig. 4 Overall survival of patients with peritoneal metastases of gastric cancer treated with cytoreductive surgery and hyperthermic intraperitoneal chemotherapy according to level of experience of the treating center (number of patients treated) $(p=0.02)$

a cytoreduction including gastrectomy in patients with a PCI $>12$ is not recommended. Our study supports this dogma. PCI above 15 results in a median survival of 5 months, whereas patients with a PCI up to 6 achieve a median survival of 18 months. These results underline the importance of the PCI and emphasize the laparoscopy as an important staging tool in advanced GC for further treatment decision making. In addition, histology allows documentation of tumor stage.

\section{Preoperative chemotherapy}

Patients with GC and low-volume PM in which complete tumor resection is a goal should obtain the currently best possible therapy [22]. The most effective preoperative treatment includes a triple combination with taxane according to the results of the randomized phase III study of the AIO (FLOT 4-study). In the meantime, this therapy regimen became more and more established in Germany [23, 24]. The majority of patients of our study cohort were treated according to the national S3-guidelines. Nevertheless, it is surprising that $26 \%$ of the patients were not treated with preoperative chemotherapy. The reasons were not stated in our registry and, therefore, remain unclear. Potential reasons for this aspect could be patients being operated due to tumor perforation or acute tumor bleeding.

\section{Cytoreductive surgery in peritoneal metastatic gastric cancer}

The complete tumor removal is the only curative therapeutic option in non-metastasized GC patients [22]. In metastatic gastric cancer, a complete tumor resection is usually not possible. In small single-center series in patients with PM from GC, a survival benefit for selected patients after CRS and HIPEC was identified [4].

Jeong et al. performed palliative gastrectomy in 162 of 197 patients affected by incurable gastric cancer with a lethality of $1.2 \%$. Patients who subsequently received additive chemotherapy had the longest survival with 13.9 months compared to those who received chemotherapy only (9.6 months) or surgery only (5.4 months) [25]. A meta-analysis of 14 publications with 3003 patients showed a significant survival benefit for patients, who underwent palliative gastrectomy. Patients with complete resected liver metastases followed by postoperative chemotherapy had the greatest survival benefit [26].

Similar data exist for the peritoneal metastatic gastric carcinoma. Complete tumor resection including removal of all peritoneal tumor nodules (CCR 0 ) is associated with a significant longer survival as compared to the incomplete tumor resection [20,21]. The goal of complete CRS is directly influenced by the extent of the tumor dissemination 
measured by the PCI [16]. The same results were found in the German database. CCR 0 was achieved in $71.6 \%$ of all patients, CCR 1 in $10.1 \%$, and CCR 2 in $5.9 \%$ and in $2.4 \%$ only debulking surgery was possible. To achieve complete cytoreduction, multivisceral resection of gallbladder, colon, rectum, ovary, and pancreas was necessary in several cases. The median survival for CCR 0 was 13 months compared to 10 months ( $p=0.19)$ (Fig. 3). However, extended surgery was also associated with a higher complication rate. Therefore, multivisceral resection should only be done if CCR O resection is achievable.

Comparing the overall survival data of these selected patient cohort with existing data of patients treated with intensive intravenous chemotherapy, it seems that patients benefit from CRS \& HIPEC treatment. Recent studies of Al-Batran et al. and a systematic review of Chan et al. demonstrated median overall survival of 10.8 months for patients with Stage IV gastric cancer treated with FLOT [27]. Subgroup analysis of our study proved that patients with incomplete cytoreduction or PCI $>15$ are not benefitting from CRS \& HIPEC due to an overall survival of 10 or 5 months, respectively [28].

\section{Hyperthermic intraperitoneal chemotherapy (HIPEC)}

The evidence for HIPEC in PM of GC is low. If the oncological benefit is questionable, HIPEC-related complications must be addressed. In a recent paper by Mi et al. HIPEC was not associated with a higher rate of anastomotic leakage, ileus, bowel perforation, myelosuppression, gastrointestinal reaction, but with a higher rate of abdominal pain [29]. In the meta-analysis by Sun et al. based on 10 RCTs, a survival benefit in the group with HIPEC was shown [26]. In addition, in HIPEC treated patients, a lower number of peritoneal recurrences were seen, without a higher rate of complications. These three studies analyzed prophylactic HIPEC in patients with advanced GC without PM [30]. The latest meta-analysis showed that surgery with intraperitoneal chemotherapy (no matter the type) improves 1-, 2-, and 3 -year survival [31]. No difference in 5-year survival rate was seen. All studies lead to the result that HIPEC should offered only in the case of GC with limited PM and complete resectability of disease (CCR 0 ). However, no benefit is seen in cases of macroscopic tumor residue. Currently, in Germany, the effectiveness of HIPEC after CRS in GC with limited PM is evaluated in a Phase III study (GASTRIPECTrial) [32].

Until today, there are many unanswered questions regarding the effectiveness of HIPEC. Which are the best drugs for intraabdominal application? Drugs should be hydrosoluble, able to achieve and maintain a high ratio of intraperitoneal vs. plasmatic concentration, should have a rapid clearance, able to penetrate deep into the cancer nodules, and exert an anticancer effect on the tumor. Moreover, the tumor should be chemosensitive with respect to the drug. In addition, the drug directly expose his antineoplastic activity without antimetabolites [33].

Because of the high area under the curve ratios, between intraperitoneal exposure and systemic agents, paclitaxel, docetaxel, gemcitabine, and doxorubicin were ideal drugs for intraperitoneal administration [34]. Despite the lack of clinical trials comparing the effects of the different regimens, evidence comes from experimental studies. These showed that MMC and CDDP have performed better than many other drugs in terms of intraperitoneal delivery [33, $35]$; consequently, these drugs are used most frequently in the perfusate, either alone or in combination $[9,21,36,37]$. In this series, in $26 \%$ of patients, HIPEC received monochemotherapy and MMC was used in $16 \%$. Dual drug combinations were applied in $73.6 \%$. Mostly, the combination of CDDP \& Doxorubicin (53\%) and CDDP \& MMC (18\%) was given. Oxaliplatin alone or in combination was only used in $4 \%$. We found no difference in survival between mono and dual drug combination.

The duration of the HIPEC was $62.5+17.9$ min with a mean temperature of $41.7+0.7^{\circ} \mathrm{C}$. The French groups used a different drug and a different duration. They use oxaliplatin for $30 \mathrm{~min}$ at $43{ }^{\circ} \mathrm{C}$ as a standard procedure. The median overall survival was 9.2 months, whereas the German regimen revealed 13 months (95\% CI 9.1-16.9) (Fig. 2) [21]. This could be explained by the learning process in patient selection, because the German database started 2008, 9 years after the French experience.

\section{Mortality and morbidity in HIPEC}

Aggressive treatment and perioperative chemotherapy are usually associated with a higher rate of severe morbidity and mortality.

Al-Batran reported medical and surgical complications in 44 of 111 patients (40\%) in the ECF/ECX group and 30 of 119 patients (25\%) in the FLOT group [23]. However, Costa et al. demonstrated acceptable complications of $20 \%$ grade 3 morbidity in association of perioperative systemic and intraperitoneal chemotherapy after radical surgery [38].

Huang et al. investigated safety and efficacy of intraperitoneal chemotherapy. The perioperative mortality was $2.3 \%$. Severe complications occurred in $15.6 \%$, intraabdominal abscess in $13.4 \%$, anastomotic leakage in $2.3 \%$, postoperative ileus in $1.6 \%$, bowel perforation in $2.2 \%$, pancreatic fistula $3.6 \%$, and bone-marrow depression in 5\% [39].

Our analysis revealed a major complication rate of $17.4 \%$. Twelve patients $(5.1 \%)$ died after CRS and HIPEC. There is a difference if patients were treated in an experienced center. In centers with more than 20 CRS plus HIPEC, 
the postoperative complication rate was lower compared to centers with less than 20 procedures. The median survival was 16 months compared to 12 months in low-volume institutions. A potential explanation for this difference is patient selection and experience, as the PCI is lower and the completeness of cytoreduction significantly higher in high-volume centers. These facts combined with a lower postoperative complication rate might explain the difference in median overall survival.

The effect of HIPEC after complete CRS is under evaluation and might be answered by the GASTRIPEC trial. The results are awaited in the next years. Chemotherapeutic regime as well as duration of HIPEC, dosage, patient characteristics, temperature, carrier solution, intraperitoneal pressure, open or closed technique, warrants more experimental and clinical studies to determine the influence of each individual variable on toxicity profile and treatment outcome.

\section{Limitations}

One major limitation of a national database is the quality of the data with missing values and limited follow-up information of the patients. In total, $50 \%$ of all cases of the registry were treated in certified centres which committed to have a recurrent audit process and a minimum annual case load of 15 CRS\&HIPEC.

\section{Conclusions}

Hyperthermic intraperitoneal chemotherapy (HIPEC) after complete cytoreduction in GC with PM can be performed with acceptable morbidity and mortality. To achieve good results a preoperative intensive workup for patient selection should be done. This includes staging laparoscopy and documentation of the PCI. Only patients with low PCI followed by complete cytoreduction are able to achieve longterm survival. The best results were reached in experienced centers, with more than 20 included patients treated with CRS \& HIPEC.

Acknowledgements StuDoQ|Peritoneum registry provided by the Study, documentation and quality center (StuDoQ) of the German Society for general Surgery (DGAV). Peritoneum Surface Oncology Group and members of the StuDoQ-HIPEC Registry of the German Society for General and Visceral Surgery (DGAV)

\section{Compliance with ethical standards}

Conflict of interest The authors declare that they have no conflict of interest.

Ethical approval All procedures followed were in accordance with the ethical standards of the responsible committee on human experimenta- tion (institutional and national) and with the Helsinki Declaration of 1964 and later versions.

Informed consent Informed consent or substitute for it was obtained from all patients included in the study.

\section{References}

1. Ferlay J, Soerjomataram I, Dikshit R, Eser S, Mathers C, Rebelo $\mathrm{M}$, et al. Cancer incidence and mortality worldwide: sources, methods and major patterns in GLOBOCAN 2012. Int J Cancer. 2015;136(5):E359-E386. https://doi.org/10.1002/ijc.29210.

2. Ajani JA, Bentrem DJ, Besh S, D'Amico TA, Das P, Denlinger C, et al. Gastric cancer, version 2.2013: featured updates to the NCCN Guidelines. J Natl Compr Canc Netw. 2013;11(5):531-46.

3. Chang JS, Kim KH, Keum KC, Noh SH, Lim JS, Kim HS, et al. Recursive partition analysis of peritoneal and systemic recurrence in patients with gastric cancer who underwent D2 gastrectomy: implications for neoadjuvant therapy consideration. J Surg Oncol. 2016;114(7):859-64. https://doi.org/10.1002/jso.24405.

4. Seyfried F, von Rahden BH, Miras AD, Gasser M, Maeder U, Kunzmann V, et al. Incidence, time course and independent risk factors for metachronous peritoneal carcinomatosis of gastric origin-a longitudinal experience from a prospectively collected database of 1108 patients. BMC Cancer. 2015;15:73. https://doi. org/10.1186/s12885-015-1081-8.

5. Yonemura Y, Endou Y, Sasaki T, Hirano M, Mizumoto A, Matsuda T, et al. Surgical treatment for peritoneal carcinomatosis from gastric cancer. Eur J Surg Oncol. 2010;36(12):1131-8. https ://doi.org/10.1016/j.ejso.2010.09.006.

6. Roviello F, Caruso S, Neri A, Marrelli D. Treatment and prevention of peritoneal carcinomatosis from gastric cancer by cytoreductive surgery and hyperthermic intraperitoneal chemotherapy: overview and rationale. Eur J Surg Oncol. 2013;39(12):1309-16. https://doi.org/10.1016/j.ejso.2013.10.010.

7. Di Vita M, Cappellani A, Piccolo G, Zanghi A, Cavallaro A, Bertola $\mathrm{G}$, et al. The role of HIPEC in the treatment of peritoneal carcinomatosis from gastric cancer: between lights and shadows. Anticancer Drugs. 2015;26(2):123-38. https://doi.org/10.1097/ CAD.0000000000000179.

8. Sugarbaker PH, Cunliffe WJ, Belliveau J, de Bruijn EA, Graves $\mathrm{T}$, Mullins RE, et al. Rationale for integrating early postoperative intraperitoneal chemotherapy into the surgical treatment of gastrointestinal cancer. Semin Oncol. 1989;16(4 Suppl 6):83-97.

9. Yang XJ, Huang CQ, Suo T, Mei LJ, Yang GL, Cheng FL, et al. Cytoreductive surgery and hyperthermic intraperitoneal chemotherapy improves survival of patients with peritoneal carcinomatosis from gastric cancer: final results of a phase III randomized clinical trial. Ann Surg Oncol. 2011;18(6):1575-81. https://doi. org/10.1245/s10434-011-1631-5.

10. Sun Y, Shen P, Stewart JH, Russell GB, Levine EA. Cytoreductive surgery and hyperthermic intraperitoneal chemotherapy for peritoneal carcinomatosis from small bowel adenocarcinoma. Am Surg. 2013;79(6):644-8.

11. Tokunaga M, Terashima M, Tanizawa Y, Bando E, Kawamura $\mathrm{T}$, Yasui $\mathrm{H}$, et al. Survival benefit of palliative gastrectomy in gastric cancer patients with peritoneal metastasis. World J Surg. 2012;36(11):2637-43. https://doi.org/10.1007/s0026 8-012-1721-y.

12. Rovers KP, Simkens GA, Vissers PA, Lemmens VE, Verwaal VJ, Bremers AJ, et al. Survival of patients with colorectal peritoneal metastases is affected by treatment disparities among hospitals 
of diagnosis: a nationwide population-based study. Eur J Cancer. 2017;75:132-40. https://doi.org/10.1016/j.ejca.2016.12.034.

13. Verwaal VJ, Rau B, Jamali F, Gilly FN, de Hingh I, Takala H, et al. Registries on peritoneal surface malignancies throughout the world, their use and their options. Int J Hyperthermia. 2017;33(5):528-33. https://doi.org/10.1080/02656736.2017.1315178.

14. Sugarbaker PH. The Seven Best from PSOGI 2016. Ann Surg Oncol. 2017;24(4):870-4. https://doi.org/10.1245/s10434-017-5793-7.

15. Lutz MP, Zalcberg JR, Ducreux M, Ajani JA, Allum W, Aust D et al. Highlights of the EORTC St. Gallen International Expert Consensus on the primary therapy of gastric, gastroesophageal and oesophageal cancer-differential treatment strategies for subtypes of early gastroesophageal cancer. Eur J Cancer. 2012;48(16):2941-53. https:// doi.org/10.1016/j.ejca.2012.07.029.

16. Jacquet $\mathrm{P}$, Sugarbaker PH. Clinical research methodologies in diagnosis and staging of patients with peritoneal carcinomatosis. Cancer Treat Res. 1996;82:359-74.

17. Glehen O, Osinsky D, Cotte E, Kwiatkowski F, Freyer G, Isaac S, et al. Intraperitoneal chemohyperthermia using a closed abdominal procedure and cytoreductive surgery for the treatment of peritoneal carcinomatosis: morbidity and mortality analysis of 216 consecutive procedures. Ann Surg Oncol. 2003;10(8):863-9.

18. Dindo D, Demartines N, Clavien PA. Classification of surgical complications: a new proposal with evaluation in a cohort of 6336 patients and results of a survey. Ann Surg. 2004;240(2):205-13.

19. Wittekind C. TNM Klassifikation maligner Tumoren. Weinheim: Praktikerbuch; 2017.

20. Gill RS, Al-Adra DP, Nagendran J, Campbell S, Shi X, Haase E, et al. Treatment of gastric cancer with peritoneal carcinomatosis by cytoreductive surgery and HIPEC: a systematic review of survival, mortality, and morbidity. J Surg Oncol. 2011;104(6):692-8. https:// doi.org/10.1002/jso.22017.

21. Glehen O, Gilly FN, Arvieux C, Cotte E, Boutitie F, Mansvelt $\mathrm{B}$, et al. Peritoneal carcinomatosis from gastric cancer: a multiinstitutional study of 159 patients treated by cytoreductive surgery combined with perioperative intraperitoneal chemotherapy. Ann Surg Oncol. 2010;17(9):2370-7. https://doi.org/10.1245/s1043 4-010-1039-7.

22. Moehler M, Baltin CT, Ebert M, Fischbach W, Gockel I, Grenacher $\mathrm{L}$, et al. International comparison of the German evidence-based S3-guidelines on the diagnosis and multimodal treatment of early and locally advanced gastric cancer, including adenocarcinoma of the lower esophagus. Gastric Cancer. 2015;18(3):550-63. https:// doi.org/10.1007/s10120-014-0403-x.

23. Al-Batran SE, Hofheinz RD, Pauligk C, Kopp HG, Haag GM, Luley $\mathrm{KB}$, et al. Histopathological regression after neoadjuvant docetaxel, oxaliplatin, fluorouracil, and leucovorin versus epirubicin, cisplatin, and fluorouracil or capecitabine in patients with resectable gastric or gastro-oesophageal junction adenocarcinoma (FLOT4-AIO): results from the phase 2 part of a multicentre, open-label, randomised phase 2/3 trial. Lancet Oncol. 2016;17(12):1697-708. https://doi. org/10.1016/S1470-2045(16)30531-9.

24. Al-Batran SE, Hozaeel W, Tauchert FK, Hofheinz RD, Hinke A, Windemuth-Kieselbach $\mathrm{C}$, et al. The impact of docetaxel-related toxicities on health-related quality of life in patients with metastatic cancer (QoliTax). Ann Oncol. 2015;26(6):1244-8. https://doi. org/10.1093/annonc/mdv129.

25. Jeong O, Park YK, Choi WY, Ryu SY. Prognostic significance of non-curative gastrectomy for incurable gastric carcinoma. Ann Surg Oncol. 2014;21(8):2587-93. https://doi.org/10.1245/s1043 4-014-3638-1.

26. Sun J, Song Y, Wang Z, Chen X, Gao P, Xu Y, et al. Clinical significance of palliative gastrectomy on the survival of patients with incurable advanced gastric cancer: a systematic review and meta-analysis. BMC Cancer. 2013;13:577. https://doi. org/10.1186/1471-2407-13-577.
27. Spoerl S, Novotny A, Al-Batran SE, Lordick F, Thuss-Patience P, Pauligk C, et al. Histopathological regression predicts treatment outcome in locally advanced esophagogastric adenocarcinoma. Eur J Cancer. 2018;90:26-33. https://doi.org/10.1016/j.ejca.2017.11.020.

28. Chan DL, Sjoquist KM, Goldstein D, Price TJ, Martin AJ, Bang YJ, et al. The effect of anti-angiogenic agents on overall survival in metastatic oesophago-gastric cancer: a systematic review and metaanalysis. PLoS One. 2017;12(2):e0172307. https://doi.org/10.1371/ journal.pone.0172307.

29. Mi DH, Li Z, Yang KH, Cao N, Lethaby A, Tian JH, et al. Surgery combined with intraoperative hyperthermic intraperitoneal chemotherapy (IHIC) for gastric cancer: a systematic review and meta-analysis of randomised controlled trials. Int J Hyperthermia. 2013;29(2):156-67. https://doi.org/10.3109/02656736.2013.76835 9.

30. Yan TD, Black D, Sugarbaker PH, Zhu J, Yonemura Y, Petrou G, et al. A systematic review and meta-analysis of the randomized controlled trials on adjuvant intraperitoneal chemotherapy for resectable gastric cancer. Ann Surg Oncol. 2007;14(10):2702-13. https://doi. org/10.1245/s10434-007-9487-4.

31. Coccolini F, Cotte E, Glehen O, Lotti M, Poiasina E, Catena F, et al. Intraperitoneal chemotherapy in advanced gastric cancer. Meta-analysis of randomized trials. Eur J Surg Oncol. 2014;40(1):12-26. https ://doi.org/10.1016/j.ejso.2013.10.019.

32. Rau B. Prospective multicentric phase III study. Z Gastroenterol. 2014;52(3):262.

33. Yonemura Y, Elnemr A, Endou Y, Hirano M, Mizumoto A, Takao $\mathrm{N}$, et al. Multidisciplinary therapy for treatment of patients with peritoneal carcinomatosis from gastric cancer. World J Gastrointest Oncol. 2010;2(2):85-97. https://doi.org/10.4251/wjgo.v2.i2.85.

34. Van der Speeten K, Stuart OA, Sugarbaker PH. Pharmacology of perioperative intraperitoneal and intravenous chemotherapy in patients with peritoneal surface malignancy. Surg Oncol Clin N Am. 2012;21(4):577-97. https://doi.org/10.1016/j.soc.2012.07.013.

35. Hildebrandt B, Rau B, Gellermann J, Wust P, Riess H. Hyperthermic intraperitoneal chemotherapy in patients with peritoneal carcinosis. J Clin Oncol. 2004;22(8):1527-9. https://doi.org/10.1200/ JCO.2004.99.293.

36. Fujimoto S, Takahashi M, Kobayashi K, Kure M, Masaoka H, Ohkubo H, et al. Combined treatment of pelvic exenterative surgery and intra-operative pelvic hyperthermochemotherapy for locally advanced rectosigmoid cancer: report of a case. Surg Today. 1993;23(12):1094-8.

37. Wu HT, Peng KW, Ji ZH, Sun JH, Zhang Q, Yang XJ, et al. Cytoreductive surgery plus hyperthermic intraperitoneal chemotherapy with lobaplatin and docetaxel to treat synchronous peritoneal carcinomatosis from gastric cancer: results from a Chinese center. Eur J Surg Oncol. 2016;42(7):1024-34. https://doi.org/10.1016/j. ejso.2016.04.053.

38. Costa WL Jr, Coimbra FJ, Ribeiro HS, Diniz AL, de Godoy AL, Begnami M, et al. Safety and preliminary results of perioperative chemotherapy and hyperthermic intraperitoneal chemotherapy (HIPEC) for high-risk gastric cancer patients. World J Surg Oncol. 2012;10:195. https://doi.org/10.1186/1477-7819-10-195.

39. Huang JY, Xu YY, Sun Z, Zhu Z, Song YX, Guo PT, et al. Comparison different methods of intraoperative and intraperitoneal chemotherapy for patients with gastric cancer: a meta-analysis. Asian Pac J Cancer Prev. 2012;13(9):4379-85.

Publisher's Note Springer Nature remains neutral with regard to jurisdictional claims in published maps and institutional affiliations. 


\section{Affiliations}

Beate Rau ${ }^{1}$ (1) $\cdot$ Andreas Brandl ${ }^{1}$ · Pompiliu Piso ${ }^{2}$. Jörg Pelz Peter Busch $^{4} \cdot$ Cedric Demtröder $^{5} \cdot$ Silke Schüle $^{6}$. Hans-Jürgen Schlitt ${ }^{7}$. Marc Roitman ${ }^{8}$. Jürgen Tepel ${ }^{9}$. Udo Sulkowski ${ }^{10}$ • Faik Uzunoglu ${ }^{11}$ - Michael Hünerbein ${ }^{12}$. Rüdiger Hörbelt ${ }^{13}$. Michael Ströhlein ${ }^{14}$. Stefan Beckert ${ }^{15}$. Ingmar Königsrainer ${ }^{15}$. Alfred Königsrainer ${ }^{15}$. for the Peritoneum Surface Oncology Group and members of the StuDoQ|Peritoneum Registry of the German Society for General and Visceral Surgery (DGAV)

1 Department of Surgery, Campus Virchow-Klinikum and Charité Campus Mitte, Charité-Universitätsmedizin Berlin, Augustenburger Platz 1, 13353 Berlin, Germany

2 Department of General and Visceral Surgery, Barmherzige Brueder Hospital Regensburg, Regensburg, Germany

3 Department of General, Visceral, and Oncologic Surgery, St. Bernward Hospital, Hildesheim, Germany

4 Department of Visceral, General Surgery, Agatharied Hospital, Hausham, Germany

5 Department of General Surgery and Therapy Center for Peritoneal Carcinomatosis, Marien Hospital Herne, Ruhr-Universität Bochum, Herne, Germany

6 Department of General, Visceral and Vascular Surgery, University Hospital of Jena, Jena, Germany

7 Department of Surgery, University Hospital Regensburg, Regensburg, Germany

8 Surgical Center and Asklepios Tumor Center, Asklepios Paulinen Klinik, Wiesbaden, Germany
9 Clinic for General, Thoracic and Visceral Surgery, Klinikum Osnabrück, Osnabrück, Germany

10 Department of General, Visceral and Vascular Surgery, Clemenshospital, Münster, Germany

11 Department of General, Visceral and Thoracic Surgery, University Medical Centre, Hamburg-Eppendorf, Hamburg, Germany

12 Department of General, Visceral and Cancer Surgery, HELIOS Klinikum Berlin-Buch, Berlin, Germany

13 Department of General, Visceral, Thoracic, Transplant and Pediatric Surgery, University Hospital Gießen, Gießen, Germany

14 Department of Abdominal, Vascular and Transplant Surgery, Cologne-Merheim Medical Center, Witten/Herdecke University, Cologne, Germany

15 Department of Surgery, Comprehensive Cancer Center, University of Tübingen, Tübingen, Germany 